\title{
Report of Beta Thalassemia in Newar Ethnicity
}

\author{
Rajendra Dev Bhatt ${ }^{1 *}$, Surendra Koju ${ }^{2}$, Prabodh Risal ${ }^{1}$
}

\section{Affiliations:}

${ }^{1}$ Department of Clinical Biochemistry, Dhulikhel Hospital, Kathmandu University Hospital

${ }^{2}$ Department of Pathology, Dhulikhel Hospital, Kathmandu University Hospital, Dhulikhel Kavre, Nepal

\section{Correspondence to:}

Rajendra Dev Bhatt

Department of Biochemistry

Kathmandu University School of Medical Sciences

Dhulikhel Hospital, Dhulikhel, Kavre, Nepal

bhattdev.rajendra@gmail.com

\section{How to cite this Article:}

Bhatt. R.D. Koju. S. Risal.P. Report of Beta

Thalassemia in Newar Ethnicity. Ann.Clin.Chem.Lab.

Med.2017:3(1):30-34

DOI: http://dx.doi.org/10.3126/acclm.v3i1.17298

\section{(C) 2017 Nepalese Association for Clinical Chemistry}

\begin{abstract}
Beta thalassemia trait is a heterogeneous autosomal recessive form of beta thalassemia. Individual with beta thalassemia are clinically asymptomatic. Here we have described a case that has been incidentally diagnosed as beta thalassemia trait. A 31 year old male form Newar Community came to hospital for routine health checkup was send for hematological investigation. On examination, his red cell morphology was found to be microcytic hypochromic and his hemoglobin concentration was mildly decrease. His other parameters was evaluated and requested for analysis of iron profile and hemoglobin electrophoresis. Iron profile test was normal. Hemoglobin electrophoresis showed prominent band in $\mathrm{HbA} 2$ region. Presence of $\mathrm{HbA} 2$ band was confirmed by hemoglobin variant HPLC analysis. A diagnosis of heterozygous beta thalassemia trait was made. Prevalence of beta thalassemia gene in Tharu population was reported but its presence in other communities is still unknown therefore, it is recommended to study the prevalence of beta thalassemia gene in Newar ethnicity as well.
\end{abstract}

KEY WORDS: Beta Thalassemia, Hemoglobin variant, $\mathrm{HbA} 2$ 


\section{INTRODUCTION}

Beta thalassemia are heterogeneous autosomal recessive inherited disorder characterize by reduce or absent synthesis of beta globin chain synthesis that cause early lysis of red blood cell and leads to ineffective erythropoiesis ${ }^{1}$. Betathalassemia is most common among populations of Mediterranean, African, South Asian and central Asian ancestry. Migration and inter -marriage between different ethnic groups contribute thalassemia presence in worldwide. Approximately $5 \%$ of world populations are affected by mutation in alpha of beta globin chain of hemoglobin and the affected individual may be symptomatic or silent carrier. About $1.5 \%$ of global populations are carrier of beta thalassemia ${ }^{2}$. It is estimated that carrier of beta thalassemia gene is higher in Tharu population among Nepalese population but beta thalassemia gene carrier form other communities are still unknown.

The clinical presentation of homozygous beta thalassemia major is severe transfusion dependent anemia while individual with beta thalassemia trait are clinically asymptomatic. Diagnosis of thalassemia can be done by analysis of hemoglobin variant. In beta thalassemia minor, quantitative measurement of $\mathrm{HbA} 2$ confirm the diagnosis.

The aim of this case study is to bring awareness on presence of beta thalassemia in Newar community and need of its early detection that will help in preventing future reproductive risk.

\section{CASE REPORT}

Delta-Beta thalassemia is an unusual variant of thalassemia with elevated level of foetal hemoglobin $(\mathrm{HbF})$. The clinical presentation of delta-beta thalassemia is mild in both heterozygote and homozygote cases. We hereby describe a rare cause of elevated $\mathrm{Hb} \mathrm{F}$ in a father and his two daughters. A 52 years old diabetic male patient, on evaluation of chromatogram of cation exchange HPLC for $\mathrm{HbAlc}$, we incidentally identified elevated $\mathrm{Hb}$ F of approximately $20 \%$. Hematological investigation of the patient revealed decreased hemoglobin, normal RBC, leucocyte and platelet count, decreased $\mathrm{MCV}$ and $\mathrm{MCH}$. Red cell morphology showed predominantly normo- cytic normochromic cells with mild anisopoikilocytosis, few microcytes and hypochromic cells seen. His liver function test was normal. Haemoglobin variant analysis revealed decreased $\mathrm{Hb} \mathrm{A}(79.4 \%)$, normal $\mathrm{Hb}$ A2 (2\%) and increased $\mathrm{Hb} F(19.75 \%)$. A possible diagnosis of heterozygous $\beta$-thalassemia was considered. Since most laboratories perform $\mathrm{HbAlc}$ by cation exchange HPLC method, a careful evaluation of the chromatogram yields useful information. In our case, the elevated $\mathrm{Hb} \mathrm{F}$ in a father and further careful evaluation of clinical and hematological parameters in the family members made us to possibly think of rare disorders like heterozygous Delta-Beta thalassemia in the family and provide valuable genetic counseling.

A 32-year-old individual came to hospital for general health checkup. Clinical examination of individual revealed no sign and symptoms of any disease. He was send for laboratory investigation.

His hematological investigation showed hemoglobin $(\mathrm{Hb}) 12.6 \mathrm{~g} / \mathrm{dl}$; TLC 8,000 cells/ $\mu \mathrm{l}$; platelet count $3.5 \mathrm{lakh} / \mu \mathrm{l}$ and red blood cell (RBC) count 5.8 million/ $\mu 1$. His mean cell volume (MCV) was 62fl, mean cell hemoglobin $(\mathrm{MCH})$ was 22pgandred cell distribution width-coefficient of variation (RDW-

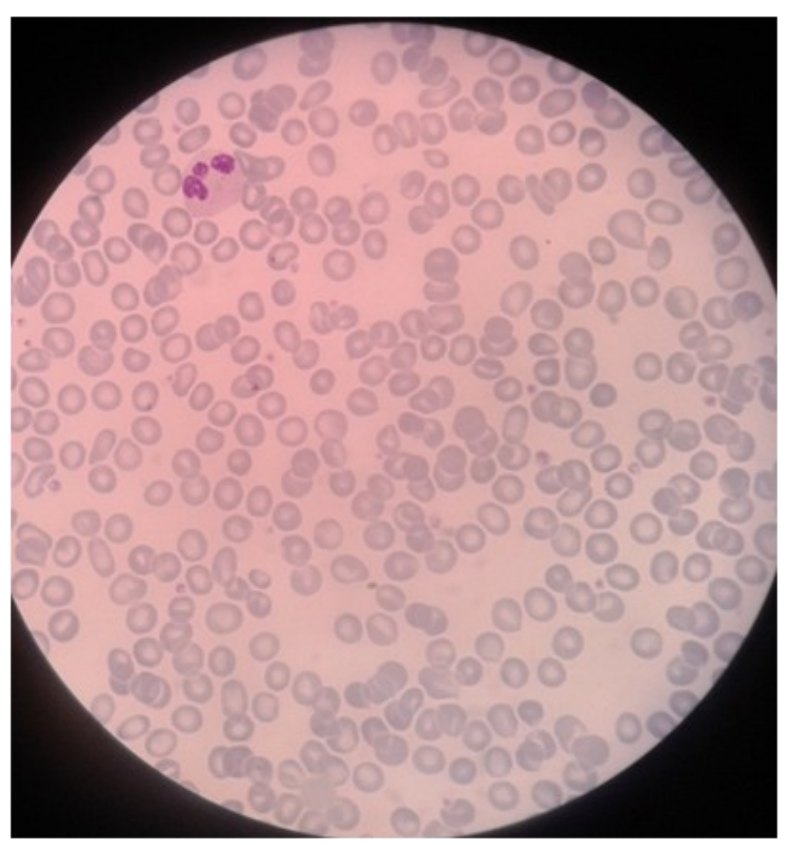

Figure 1: Peripheral blood smear showing microcytic hypochromic red cells 


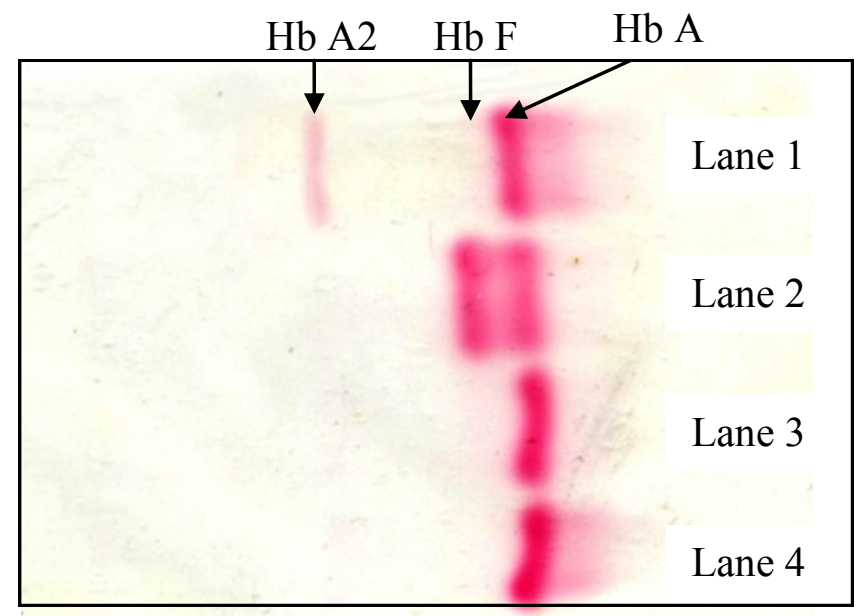

Figure 2: Hemoglobin Electrophoresis in cellulose acetate paper (Lane 1: Patient Sample, Lane 2: Newborn Sample, lane 3 and 4: Adult sample)
$\mathrm{Hb} F(2.0 \%)$ increased $\mathrm{Hb}$ A2 (6.9\%) and other unknown hemoglobin of $1.1 \%$. Since $\mathrm{Hb} \mathrm{A} 2$ was greater than $3.5 \%$, he was confirmed as beta thalassemia trait.

In view of Hemoglobin variant analysis, $\mathrm{Hb}$ electrophoresis, hematological parameters and peripheral blood smear findings, a diagnosis of beta thalassemia trait was considered. Genetic analysis could not be performed due to financial constraints. Screening of the family members was advised and genetic counseling was done.

\section{DISCUSSION}

Beta Thalassemia is a most common globin chain disorder worldwide that is characterized by abnormalities in beta globin chain synthesis resulting in reduced hemoglobin in red blood

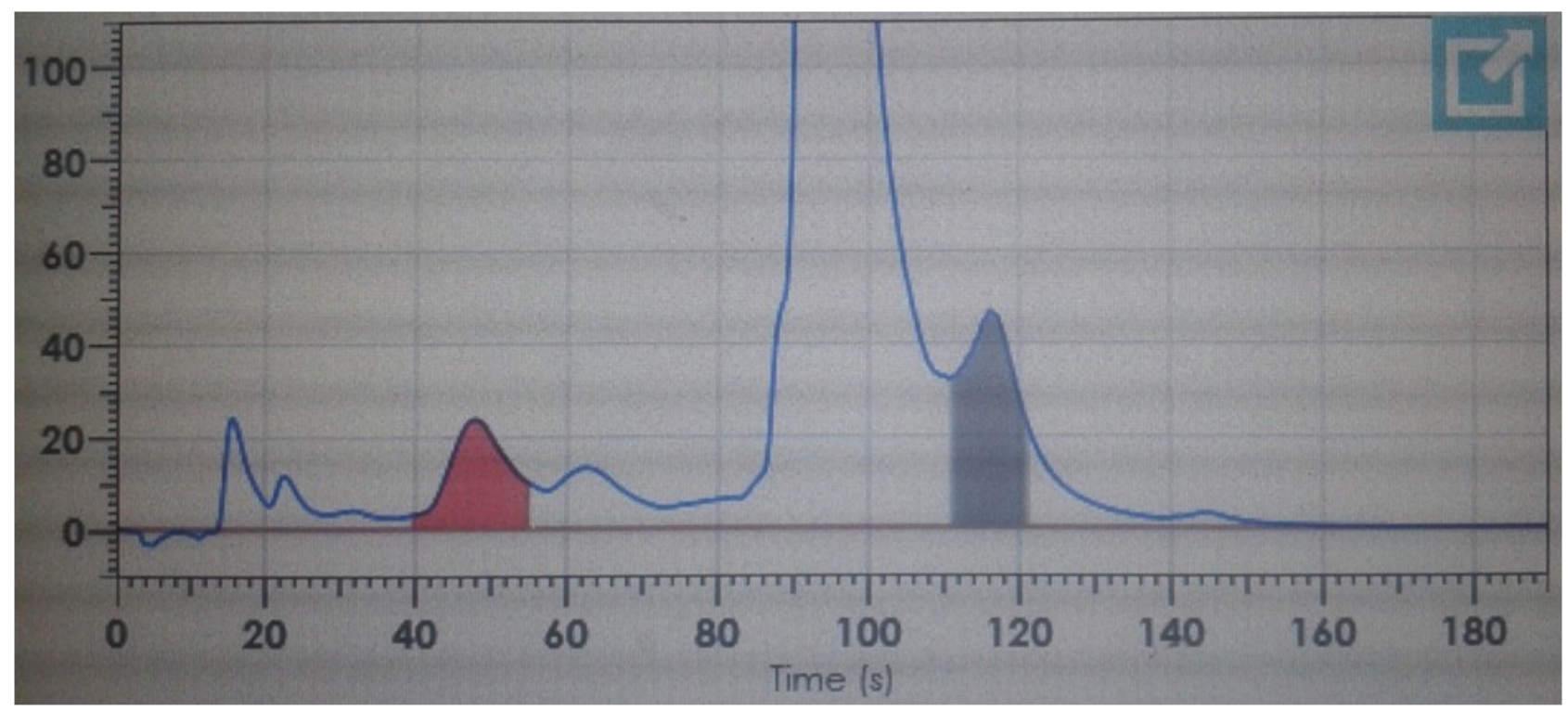

Figure 3: Hemoglobin variant separation by HPLC

CV) was $13.5 \%$. Peripheral blood smear finding was microcytic hypochromic red cell. His reticulocyte count was found to be $5.2 \%$. His liver function test was normal level.

With these parameters he was suspected for thalassemia trait. But, initially iron profile test was done to exclude iron deficiency anemia. All parameters of iron profile test was normal. He was advised for hemoglobin electrophoresis for evaluation of abnormal hemoglobin. A short and prominent band was observed in $\mathrm{HbA} 2$ region. A confirmation of band seen was done by separation of hemoglobin variant in cation exchange high performance liquid chromatography (HPLC). Hemoglobin variant analysis revealed normal $\mathrm{Hb} \mathrm{A}(90 \%)$, normal cell. Thalassemia is inherited in autosomal recessive pattern and have become a global problem.

Hemoglobin $(\mathrm{Hb})$ A $(\alpha 2 \beta 2)$ is the major hemoglobin component in postnatal life that account for $96 \%$ of total $\mathrm{Hb}$, followed by $\mathrm{HbA} 2(\alpha 2 \delta 2)$ representing $2.5-3.5 \%$ of the total, and $\mathrm{HbF}(\alpha 2 \gamma 2)$ constituting less than $1 \%$. In beta thalassemia, alteration in these hemoglobin variant is observed due to mutation in beta globin chain. Beta thalassemia has wide range of clinical variability based on types of thalassemia. Patient with thalassemia major have severe transfusion dependent anemia with hepatosplenomegaly and this type of disorder 
come in attention within first two years of life normal leukocyte and platelet count but while thalassemia intermedia have mild to decreased MCV and MCH. Peripheral smear for moderate form of anemia that rarely need trans- red cell morphology showed microcytic fusion and may be accompanied by mild hypochromic red cells. Liver function test was hepatosplenomegaly. Beta thalassemia traits are normal. Hemoglobin electrophoresis showed clinically asymptomatic which can be defined prominent band at $\mathrm{HbA} 2$ region. Hemoglobin only by specific hematological feature. ${ }^{1,3}$

Microcytic hypochromic red cell morphology is typical feature of thalassemia. But mcirocytosisis also seen in iron deficiency anemia (IDA). Hence, the resemblance between thalassemia and iron deficiency anemia can confuse the diagnosis of either disorder. Iron profile test help in differentiation of IDA from thalassemia. Iron profile test is normal in thalassemia. Many cell count based indices have been developed that can differentiate IDA from thalassemia trait. Mentzer index if most sensitive index in differentiating thalassemia trait from IDA. ${ }^{4}$

For confirmation of thalassemia, analysis of hemoglobin variant can be done. In beta thalassemia major, $\mathrm{Hb} \mathrm{A}$ is absent and $\mathrm{Hb} \mathrm{F}$ represent about $92-95 \%$ of total hemoglobin and thalassemia intermedia constitute $\mathrm{HbA}$ and $\mathrm{HbF}$ are around $10-30 \%$ and $70-90 \%$ respectively while $\mathrm{HbA} 2$ is increased in beta thalassemia trait. In thalassemia trait, hemoglobin level in normal or may be mild anemia while red cell morphology is microcytic hypochromic. And for confirmation of thalassemia trait, analysis of hemoglobin variant is preferred for evaluation of level of $\mathrm{Hb}$ A2.Typically beta thalassemia trait is diagnosed by analysis of RBC indices, which shows Microcytosis (low MCV) and reduced content of $\mathrm{Hb}$ per red cell (low $\mathrm{MCH}$ ), and by analysis of hemoglobin variant that shows the increase of $\mathrm{HbA} 2$.Normal range for $\mathrm{HbA} 2$ is $2.4-3.2 \%$. In thalassemia carrier it ranges from 3.6 to $7 \%$. While some cases have borderline $\mathrm{HbA} 2$ vlaue $3.2-3.6 \%$ and such cases need further evaluation. ${ }^{4,5}$

Quantitative measurement of $\mathrm{HbA} 2$ can be performed by many techniques like cellulose acetate electrophoresis, micro column chromatography, capillary electrophoresis but high performance liquid chromatography (HPLC) is preferred in many laboratories. ${ }^{6}$

In this case, this individual was asymptomatic for thalassemia trait. There was no previous history of anemia. Hematological investigations revealed mildly decrease hemoglobin with variant by HPLC revealed normal $\mathrm{HbA}$ levels and $\mathrm{Hb} \mathrm{F}$ level with increased $\mathrm{Hb} \mathrm{A} 2$ fraction. (Figure 2) The differential diagnosis of iron deficiency anemia was ruled out. Evaluation of HbA2 by HPLC provided useful information for diagnosis of beta thalassemia trait.

In this case, mild decrease in hemoglobin with reduce $\mathrm{MCV}$ and $\mathrm{MCH}$ and further careful evaluation of hematological parameters made us to possibly think of disorders like beta thalassemia trait and further test was performed for confirmation of beta thalassemia carrier state.

\section{CONCLUSION}

Any cases of normal or mild decrease in hemoglobin with reduce $\mathrm{MCV}$ and $\mathrm{MCH}$ must be evaluated carefully to prevent misdiagnosis of beta thalassemia trait. Such cases must be further evaluated by hematological parameter and abnormal hemoglobin variant. Diagnosis of such disease will help in knowing presence of beta thalassemia in our community. Early diagnosis of beta thalassemia trait will help forewarn reproductive risk that will prevent from having baby with beta thalassemia. Individual with beta thalassemia trait can be given genetic counseling. In conclusion this report highlight the need to know the prevalence of thalassemia in all community. Furthermore type of mutation by genetic testing is needed in Nepal.

\section{REFERENCES}

1. Danjou F, Anni F, GalanelloR.Beta-thalassemia: from genotype to phenotype. Haematologica 2011; 96(11): 1573-1575.

2. Galanello R, OrigaRaffaella. Beta-thalassemia. Orphanet Journal of Rare Diseases2010; 5(11)

3. Cao A, Galanello R. Beta-thalassemia.Genetics I Medicine 2010; 12: 61-76

4. Vehapoglu A, Ozgurhan G, Demir AD et.al. Hematological Indices for Differential Diagnosis of Beta Thalassemia Trait and Iron Deficiency Anemia Anemia ; Volume (2014), Article ID 576738 
5. Brancaleoni V, Pierro D, Motta I, Cappellini MD. Laboratory diagnosis of thalassemia. International Journal of laboratory hematology 2016; 38 (1), 32-40

6. Stephens D, Angastiniotis M, Baysa E. ICSH recommendations for the measurement of Haemoglobin A2.International Journal of laboratory hematology 2012; 34, 1-13. 